\title{
Editorial on management of diabetes mellitus with coronary artery disease
}

Wilbert S. Aronow

Cardiology Division, New York Medical College, Valhalla, USA

*Published in cooperation with the American Society for Preventive Cardiology (ASPC)

Submitted: 4 December 2011

Accepted: 5 December 2011

Arch Med Sci 2011; 7, 6: 928-930

DOI: 10.5114/AOMS.2011.26601

Copyright (C) 2011 Termedia \& Banach

The review article by Athyros et al. [1] is an excellent review article. I concur with the issues discussed by the authors. This editorial discusses my current approach to the management of patients with diabetes mellitus and coronary artery disease (CAD).

Patients with diabetes mellitus and CAD should be treated with optimal medical management. All modifiable risk factors should be treated. Patients should be strongly encouraged to stop smoking and be referred to a smoking cessation program.

Hypertension should be treated with the blood pressure reduced to $<140 / 90 \mathrm{mmHg}$ [2]. The initial drug of choice should be an angiotensinconverting enzyme (ACE) inhibitor [2].

The Pravastatin or Atorvastatin Evaluation and Infection Therapy-Thrombolysis in Myocardial Infarction (PROVE IT-TIMI) 22 trial enrolled 4,162 patients with an acute coronary syndrome (acute myocardial infarction with or without ST-segment elevation or high-risk unstable angina pectoris) [3]. The lowest cardiovascular events rates occurred with a systolic blood pressure between $130 \mathrm{mmHg}$ to $140 \mathrm{mmHg}$ and a diastolic blood pressure between $80 \mathrm{mmHg}$ to $90 \mathrm{mmHg}$ with a nadir of $136 / 85 \mathrm{mmHg}$. An observational subgroup analysis was performed in 6,400 of the 22, 576 persons enrolled in the International Verapamil SR-Trandolapril Study (INVEST) who had diabetes and CAD [4]. Persons were categorized as having tight control of blood pressure if they could maintain their systolic blood pressure below $130 \mathrm{mmHg}$ and their diastolic blood pressure below $85 \mathrm{~mm} \mathrm{Hg}$, usual control if they could maintain their systolic blood pressure between $130 \mathrm{mmHg}$ to $139 \mathrm{mmHg}$, and uncontrolled if their systolic blood pressure was $140 \mathrm{mmHg}$ or higher.

During 16,893 patient-years of follow-up, a cardiovascular event rate of $12.6 \%$ occurred in patients with usual control of blood pressure vs. $19.8 \%$ in patients with uncontrolled hypertension, $p<0.001$. The incidence of cardiovascular events was $12.6 \%$ in patients with usual control of blood pressure vs. $12.7 \%$ in patients with tight control of blood pressure. The allcause mortality rate was $11.0 \%$ with tight control of blood pressure vs. $10.2 \%$ with usual control of blood pressure $(p=0.06)$. When extended follow-up was included, the all-cause mortality rate was $22.8 \%$ with tight control of blood pressure vs. $21.8 \%$ with usual control of blood pressure, $p=0.04$.

Dyslipidemia should be treated. The serum low-density lipoprotein cholesterol should be reduced to $<70 \mathrm{mg} / \mathrm{dl}[5-7]$.

Diabetes mellitus should be treated with the hemoglobin $A_{1 c}$ reduced to $<7.0 \%$. Hypoglycemia must be avoided in patients with CAD. In 10, 251 
high-risk diabetics in the Action to Control Cardiovascular Risk in Diabetes (ACCORD) Study, patients randomized to intensive treatment reached a hemoglobin $A_{1 c}$ of $6.4 \%$, and patients randomized to conventional treatment reached a hemoglobin level of 7.5\% [8]. At 3.5-year follow-up, intensive therapy increased mortality $22 \%$ from $4.0 \%$ to $5.0 \%(p=0.04)$ and did not significantly reduce major cardiovascular events.

Obese diabetics with CAD must lose weight by dietary therapy and by aerobic physical activity. They should exercise for at least 30 min daily for 7 days per week with a minimum of 5 days of physical exercise per week [9].

Diabetics with CAD should be treated with aspirin, ACE inhibitors, $\beta$-blockers, and statins to reduce cardiovascular events and mortality and coronary revascularization [6, 9-13]. Angina pectoris should be treated with $\beta$-blockers and nitrates [14]. If angina persists, I would add a calcium channel blocker, and if needed, ranolazine.

In the Clinical Outcomes Utilizing Revascularization and Aggressive Drug Evaluation (COURAGE) trial, of 2, 248 patients with stable CAD randomized to optimal medical therapy plus percutaneous coronary intervention $(\mathrm{PCl})$ vs. optimal medical therapy alone, 766 patients (34\%) had diabetes mellitus, and 1,362 patients (61\%) had the metabolic syndrome [15].

At 4.6-year median follow-up, the risk of death or myocardial in infarction in patients with diabetes mellitus and in patients with the metabolic syndrome was similar in patients with and without early $\mathrm{PCl}$. On the basis of these data, I would not recommend early $\mathrm{PCl}$ to patients with diabetes mellitus or the metabolic syndrome who have stable CAD.

In the Bypass Angioplasty Revascularization Investigation 2 Diabetes (BARI 2D ) trial, 2,368 patients with diabetes mellitus and CAD were randomized to undergo either prompt coronary revascularization with intensive medical therapy or intensive medical therapy alone and to undergo either insulin-sensitization or insulin-provision therapy [16]. Randomization was stratified according to the choice of $\mathrm{PCl}$ or coronary artery bypass grafting (CABG). At 5-year follow-up, survival was $88.3 \%$ for the coronary revascularization group and $87.8 \%$ for the medical therapy alone group ( $p$ not significant) and $88.2 \%$ for the insulin-sensitization group and $87.9 \%$ for the insulin-provision group ( $p$ not significant). The incidence of freedom from major cardiovascular events was also not significantly different between the coronary revascularization and medical therapy alone groups and between the insulin-sensitization and insulin provision groups. In the $\mathrm{PCl}$ stratum, the primary endpoints of death and of death or major cardiovascular events were similar in the $\mathrm{PCl}$ and medical therapy alone groups. However, in the CABG stratum, the incidence of death or myocardial infarction or stroke was $22.4 \%$ in the CABG group vs. $30.5 \%$ in the medical therapy alone group $(p=0.01)[16]$.

In the BARI 2 D trial, 1,191 patients were randomized to optimal medical therapy alone and 1,173 patients to coronary revascularization with 796 patients preselected for $\mathrm{PCl}$ and 377 patients to CABG [17]. Compared with the medical therapy group alone, at 3-year follow-up, the coronary revascularization group had a lower incidence of worsening angina pectoris ( $8 \%$ vs. $13 \%, p<0.001$ ), a lower incidence of new angina pectoris (37\% vs. $51 \%$, $p=0.001$ ), a lower incidence of subsequent coronary revascularization ( $18 \%$ vs. $33 \%, p<0.001)$, and a higher incidence of angina-free status (66\% vs. $58 \%, p=0.003)$. The CABG patients were at higher risk than the $\mathrm{PCl}$ patients and had the greatest benefits from coronary revascularization. The symptomatic benefits were observed particularly for high-risk patients.

These data favor optimal medical therapy alone in patients with diabetes mellitus and stable CAD. However, if disabling angina pectoris despite optimal medical therapy occurs, I would recommend coronary revascularization. In high-risk patients, I would recommend $\mathrm{CABG}$ over $\mathrm{PCl}$ at this time. At 10.4-year follow-up of diabetics with CAD in the BARI trial, the CABG group had a survival rate of $57.8 \%$ vs. $45.5 \%$ for the $\mathrm{PCl}$ group $(p=0.025)$ and a subsequent coronary revascularization incidence of $20.3 \%$ for the CABG group vs. $76.8 \%$ for the $\mathrm{PCI}$ group $(p<0.001)$ [18].

On the basis of the available data, I would treat patients with diabetes mellitus and ST-segment elevation myocardial infarction [19] or unstable angina/non-ST-segment elevation myocardial infarction [20] with coronary revascularization with the choice of $\mathrm{PCl}$ or CABG depending on the coronary angiographic findings. The blood sugar in these patients should have a target goal between $140-180 \mathrm{mg} / \mathrm{dl}$. Diabetics who have received stents should be treated with dual antiplatelet therapy for at least 1 year after $\mathrm{PCl}$ and preferably longer.

\section{Acknowledgments}

The author has no conflicts of interest. He has no affiliation or financial involvement with any organization or entity with a financial interest in or financial conflict with the subject matter or materials discussed in the manuscript.

\section{References}

1. Athyros VG, Gossios TD, Tziomalos K, et al. Is there an additional benefit from coronary revascularization in diabetic patients with acute coronary syndromes or stable 
angina who are already on optimal medical treatment? Arch Med Sci 2011; 7: 1066-74.

2. Aronow WS, Fleg JL, Pepine CJ, et al. ACCF/AHA 2011 expert consensus document on hypertension in the elderly: a report of the American College of Cardiology Foundation Task Force on Clinical Expert Consensus Documents developed in collaboration with the American Academy of Neurology, American Geriatrics Society, American Society for Preventive Cardiology, American Society of Hypertension, American Society of Nephrology, Association of Black Cardiologists, and European society of Hypertension. J Am Coll Cardiol 2011; 57: 2037-114.

3. Bangalore S, Qin J, Sloan S, et al. What is the optimal blood pressure in patients after acute coronary syndromes? Relationship of blood pressure and cardiovascular events in the Pravastatin or Atorvastatin Evaluation and Infection Therapy-Thrombolysis in Myocardial Infarction (PROVE IT-TIMI) 22 trial. Circulation 2010; 122 2142-51.

4. Cooper-DeHoff RM, Gong Y, Handberg EM, et al. Tight blood pressure control and cardiovascular outcomes among hypertensive patients with diabetes and coronary artery disease. JAMA 2010; 304: 61-8.

5. Grundy SM, Cleeman JI, Merz CN, et al. Implications of recent clinical trials for the National Cholesterol Education Program Adult Treatment Panel III guidelines. Circulation 2004; 110: 227-39.

6. Aronow WS, Ahn C, Gutstein H. Reduction of new coronary events and of new atherothrombotic brain infarction in older persons with diabetes mellitus, prior myocardial infarction, and serum low-density lipoprotein cholesterol $\geq 125 \mathrm{mg} / \mathrm{dl}$ treated with statins. J Gerontol Med Sci 2002; 57A: M747-50.

7. Ravipati G, Aronow WS, Kumbar S, et al. Patients with diabetes mellitus with ischemic stroke have a higher hemoglobin $\mathrm{A}_{1 \mathrm{c}}$ level and a higher serum low-density lipoprotein cholesterol level than diabetics without ischemic stroke. Arch Med Sci 2009; 5: 391-3.

8. The Action to Control Cardiovascular Risk in Diabetes Study Group. Effects of intensive glucose lowering in type 2 diabetes. N Engl J Med 2008; 358: 2545-59.

9. Smith SC Jr, Allen J, Blair SN, et al. ACC/AHA guidelines for secondary prevention for patients with coronary and other atherosclerotic vascular disease: 2006 update: endorsed by the National Heart, Lung, and Blood Institute. Circulation 2006; 113: 2363-72.

10. Aronow WS, Ahn C. Effect of beta blockers on incidence of new coronary events in older persons with prior myocardial infarction and diabetes mellitus. Am J Cardiol 2001; 87: 780-1.

11. Aronow WS, Ahn C, Kronzon I. Reductions of incidences of new coronary events and of congestive heart failure by beta blockers alone, by angiotensin-convering enzyme inhibitors alone, and by beta blockers plus angiotensinconverting enzyme inhibitors in older persons with prior myocardial infarction and asymptomatic left ventricular systolic dysfunction. Am J Cardiol 2001; 88: 1298-300.

12. Lai HM, Aronow WS, Mercando AD, et al. The impact of statin therapy on long-term cardiovascular outcomes in an outpatient cardiology practice. Med Sci Monit 2011; 17: CR683-6.

13. Mercando AD, Lai HM, Aronow WS, et al. Reduction in atherosclerotic events through use of aggressive risk factor reduction medications: a retrospective study in an outpatient cardiology practice. Arch Med Sci 2012; 8 (in press).

14. Aronow WS, Frishman WH. Angina in the elderly. In: Aronow WS, Fleg JL, Rich MW (eds): Cardiovascular dis- ease in the elderly. Fourth edition, New York city, Informa Healthcare, 2008, pp 269-92.

15. Maron DJ, Boden WE, Spertus JA, et al. Impact of metabolic syndrome and diabetes on prognosis and outcomes with early percutaneous coronary intervention in the COURAGE (Clinical Outcomes Utilizing Revascularization and Aggressive Drug evaluation) trial. J Am Coll Cardiol 2011; 58: 131-7.

16. The BARI 2 D Study Group. A randomized trial of therapies for type 2 diabetes and coronary artery disease. N Engl J Med 2009; 360: 2503-15.

17. Dagenais GR, Lu J, Faxon DP, et al. Effect of optimal medical treatment with or without coronary revascularization on angina and subsequent revascularizations in patients with type 2 diabetes mellitus and stable ischemic heart disease. Circulation 2011; 123: 1492-500.

18. BARI Investigators. The final 10-year follow-up results from the BARI randomized trial. J Am Coll Cardiol 2007; 49: 1600-6.

19. Kushner FG, Hand M, Smith SC, Jr, et al. 2009 focused updastes: ACC/AHA guidelines for the management of patients with ST-elevation myocardial infarction (updating the 2004 guideline and 2007 focused update) and ACC/AHA /SCAl guidelines on percutaneous coronary intervention (updating the 2005 guideline and 2007 focused update). A report of the American College of Cardiology Foundation/American Heart Association Task Force on Practice Guidelines. Circulation 2009; 120: 2271-306.

20. Wright RS, Anderson JL, Adams CD, et al. 2011 ACCF/AHA focused update of the guidelines for the management of patients with unstable angina/non-ST-elevation myocardial infarction (updating the 2007 guideline). A report of the American College of Cardiology Foundation/American Heart Association Task Force on Practice Guidelines. J Am Coll Cardiol 2011; 57: 1920-59. 